\title{
Declining by Degrees: The Effect of Corporatisation on Media Education
}

\author{
Shruti Nagpal ${ }^{1}$, Dr.Ravi Chaturvedi ${ }^{2}$ \\ ${ }^{1}$ Shruti Nagpal is a Research Scholar with AJK MCRC, JMI and is Assistant Professor with VIPS, GGSIPU, \\ New Delhi \\ ${ }^{2}$ Dr. Ravi Chaturvedi is currently working as Assistant Professor with Vivekananda School of Journalism and \\ Mass Communication, VIPS, GGSIPU, New Delhi
}

\begin{abstract}
The proliferation of Journalism and Mass communication programs in both the University system and outside of it is significant. While the FTII (Film and Television Institute of India), AJKMCRC (AJK Mass Communication Research Centre), IIMC (Indian Institute of Mass Communication), TISS (Tata Institute of Social Sciences) still remain the most popular, well sought for govt run institutes, there are many other private colleges and universities like GD Goenka, KR Mangalam, Chitkara and Noida International University that have come up and are offering various programs in media studies and even the doctorate degree in Journalism and Mass communication. Not only this, several media houses including NDTV and TV Today offer the diplomas and certificate programs in media studies with a $100 \%$ guarantee of placements.

The present paper proposes to discuss the impact of corporatisation on the status of media education and research practices in India. This question regarding corporatisation merits serious attention since the purpose of higher education is the creation of knowledge, and the corporatized university spaces start with the assumption of 'students as the consumers' whose demands of study material and academic grades should be fulfilled since they have paid the requisite fee. Even the assessment of the faculty's performance is done on the basis of students' feedback which may or may not reflect the credentials of a faculty.

Through this paper, the researchers explore the manifestations of the corporatisation process in casualization of the academic professionals, the repercussions of corporate management styles and practices on university governance, curriculum decisions and academic freedom and the impact of corporate and commercial influences on academic research and the creation of knowledge society.
\end{abstract}

Keywords: Corporatisation of education, curriculum, Media Education, Media studies, media education quality, media educators, privatisation of colleges, teaching practices, theory and practice

\section{INTRODUCTION}

National Skill Development Corporation (NSDC) in a series of reports on human resource and skill requirements in various sectors, including the media and entertainment industry, estimated that approximately one million people were formally employed in the film, television, print, radio, animation and gaming sectors that constitute almost $95 \%$ of the media and entertainment industry. Given the industry estimates and growth patterns, the study suggested that by 2022, the human resource requirement in these sectors would be around 4 million. To address the unique requirements of these sectors in technical, managerial and creative abilities there are plenty of institutions, both Declining by Degrees: The Effect of Corporatisation on Media Education private and govt. where a range of courses and subjects are offered to those interested in the industry. However, the stark separation with regard to Journalism and Media education in India is at the level of Universities funded by the State and Central Governments, private universities, colleges and over a period of time the proliferation of media schools backed by the media industry. The push towards a formal education process in journalism was provided by the University Grants Commission (UGC), which, in 1977, constituted a subject panel for journalism. Today media courses are offered at graduate, post graduate and doctoral levels in different colleges. Apart from this, there are even short term certificate courses offering skill based training and employment opportunities with the media. Not only this, several media houses including NDTV and TV Today offer the diplomas and certificate programs in media studies with a $100 \%$ guarantee of placements. Almost $15 \%$ of the media schools in Delhi alone fall in this category. The Capital has 75 media institutes, 30\% of which are university-affiliated or government-run. It is estimated that the National Capital Region has double this number. Around $70 \%$ of such schools are run privately, often without the benefit of norms. 3 In short, Indian media education scenario encompasses many types of instructional programs offered by universities, colleges and academic, technical, vocational and continuing professional education institutes. There has been a large growth in the number and type of degrees and diplomas offered by a wider variety of institutions over the past decades. 
One of the consequences, according to Dave Marshall (2008: 5)4, has been the proliferation of "new 'degree' experiences that are delivered by private for-profit, private not-for-profit, non-secular, virtual and non-university institutions."

3 PN Vasanti, Media schools need to bridge quality gap, LiveMint, April 2010

4 Marshall, Dave. 2008. "Differentiation by Degrees: System Design and the Changing Undergraduate Environment in Canada." The Canadian Journal of Higher Education 38 (3).

5 Bok writes in "Universities in the Marketplace: The Commercialization of Higher Education" (Princeton, 2004).

6 William W. Bostock, The Global Corporatisation of Universities: Causes and Consequences, University of Tasmania, Australia. 1999

The issue worth considering here is that whether the courses offered by all of these institutions are doing justice to media education, whether both the theory and the practice component of the media studies taken care of by these private colleges, what exactly has been the impact of increased corporatisation on the present status of media education in our country.

\section{CORPORATISATION: MEANING AND ROLE IN EDUCATION}

Commercial influences in higher education are nothing new. "What is new about today's commercial practices is not their existence but their unprecedented size and scope".5

Today's educational institutions are busily striving to profit from teaching, research and all the other activities on campus - offering corporations the right to endow professorships, sponsor courses, bring the university's scientific discoveries to market, even advertise in campus bathrooms. Corporatisation means that universities are assumed to be very similar to large business organisations and therefore capable of being run as businesses. These universities are expected to operate like business corporations in a market place producing technical excellence in knowledge to a large number of students. These applications of technical excellence are determined by marketing considerations. The organisational principles employed under this type of set up do not produce the long-term commitment of academic staff which is usually reduced to the barest minimum in a costconscious corporatised university.6 Declining by Degrees: The Effect of Corporatisation on Media Education Here, it is useful to consider Steck's (2003: 74-75)7 definition of the corporatized university as "an institution that is characterized by processes, decisional criteria, expectations, organizational culture, and operating practices that are taken from, and have their origins in, the modern business corporation. It is characterized by the entry of the university into marketplace relationships and by the use of market strategies in university decision making." He adds that while corporatization reflects several long standing trends in educational reform, the fundamental difference is the nature and extent of the penetration of the university by the corporate economy. Universities are widely understood to have an unquantifiable impact on our individual and collective identities, our communities, our culture, and our ability to perceive and resist other powerful institutions. The university's role is understood to be so critical to informing public life and civic participation that it might even be considered "the paradigmatic institution of the public sphere" (Calhoun 2006: 10)8. Henry Giroux (2008: 148-149)9 explains why universities matter in this way:

7 Steck, Henry. 2003. "Corporatization of the University: Seeking Conceptual Clarity." Annals of the American Academy of Political and Social Science 585: 66-83.

8 Calhoun, Craig. 2006. "The University and the Public Good." Thesis Eleven 84: 7-43

9 Giroux, Henry. 2008. "Marketing the University: Corporate Power and the Academic Factory." Our Schools, Our Selves 17 (3): 147-165.

10 Slaughter and Leslie, 1997, pp. 129 -132.

"While the university should equip people to enter the workplace, it should also educate them to contest workplace inequalities, imagine democratically organized forms of work, and identify and challenge those injustices that contradict and undercut the most fundamental principles of freedom, justice, and respect for all people who constitute the global public sphere. Higher education is about more than job preparation and consciousness-raising; it is also about imagining different futures and politics as a form of intervention into public life. In contrast to the cynicism and political withdrawal fostered by media culture, education demands that citizens be able to negotiate the interface of private considerations and public issues, be able to recognize those undemocratic forces that deny social, economic, and political justice, and be willing to give some thought to the nature and meaning of their experiences in struggling for a better world"

Competition among universities has replaced the earlier paradigms of the 'community of scholars' in common pursuit of learning and may ultimately lead to a decrease in the generation of new knowledge. In their study of university corporatisation, Slaughter and Leslie found evidence that neglect of basic research was happening, and secrecy and confidentiality about research results was a common by-product of corporatisation.10 Most of these private institutes today are busy modelling themselves after business schools (Management Institutes), which have lucrative pay packages to offer to students who secure admission. Media 
institutes today promote the placements offered to students and pay packages more than promoting the course and the institute itself (The Hoot 2011).

The cost-saving measures that corporatization often brings can also affect the education students receive. Consider the ever-growing use of adjunct faculty. Journalism schools generally function with a minimal number of qualified teachers. Most of the teaching positions in the departments remain vacant for years. The syllabus runs on the magnanimity of guest lecturers from the industry (Chauhan \& Chandra 1997), though they certainly cannot be a replacement for permanent teachers who engage in regular teaching.

One aspect of corporatisation of deep concern to many is the university's role of critic of society, a role which is compromised when universities become subordinated to market forces as a result of the reduction or elimination of permanent faculty positions and the market-orientation of research and Declining by Degrees: The Effect of Corporatisation on Media Education teaching priorities. According to Veblen, academic governance, research and teaching were among the casualties of this new and more intimate relationship between universities and corporations. For example, he claimed that administrators were fixated on fundraising at the expense of academic priorities; research was an adjunct of the industrial system; and teaching was infected by the elevation of impersonal, mechanical relations in the place of personal guidance. The consequences of this new relationship, in his view, were so far reaching that it left its mark on the "ideals, aims, methods and standards" of scholars and scholarship (p. 7). From the perspective of media education and higher learning, Veblen considered these developments "wholly untoward, not to say disastrous" (p. 178).11

11 Veblen, Thorstein. 1918. The Higher Learning in America: A Memorandum on the Conduct of Universities by Business Men. New York: B.W. Huebsch [quotes taken from Kila, Montana: Kessinger, 2004].

12 Porter, p. 628

13 Sainath, P. (2001, June). None so blind as those who will not see. The UNESCO Courier, 54 (6), 44-46.

Many of the consequences of corporatisation are seen in changes to the style and outcomes of university administration that plays a key role in appointments, examination and the handling of money. As Porter stated 'education and training constitute perhaps the greatest single long-term leverage point available to all levels of government in upgrading industry.' 12

\section{SKILL BASED EDUCATION IN MEDIA: THEORY VS. PRACTICE}

The present task confronting academics, administrators and societies is to build upon those aspects of higher education corporatisation that are positive by minimising or neutralising the harmful aspects of the process by rejecting the idea that a university should follow market trends and reaffirm its special role as an institution dedicated to the pursuit of significant knowledge and lasting values.

Sona Jha, head of TV Today's training institute in Delhi, says that one of the biggest benefits of such set-ups is that students get the right kind of training. "We give them specific training. They are trained under the supervision of real-life journalists, and that helps." Mridula Ujjwal, general manager of Pioneer Media School, says that, often, in-house media institutes are more practical in their approach because they are looking to fill jobs immediately after graduation. Modern journalism education in India is struggling to find the right balance between imparting practical skills to its students and enhancing conceptual depth and critical thinking. Justice Markandey Katju, Chairman of the Press Council of India talking of the Journalism institutes laid stress on developing the field as it is still not treated at par with other traditional disciplines of knowledge. To attain this status, it needs a culture of intellectual debate and research which will produce new body of knowledge. Unlike other disciplines in the natural sciences and social sciences, media studies lack a continuous theoretical tradition, a rigorous body of scholarly work and research that gives the discipline an identity of its own.

\section{IMPACT OF CORPORATISATION ON MEDIA EDUCATION}

Media education has undergone tremendous changes in title and type of courses available, in an attempt to satisfy the need of the industry in the last decade. Consequently, media market is flooded by professionals who are generalists and need further training to deliver quality work. Food courts, spa-like athletic facilities, and elaborate performing-arts centers are increasingly common on college and university campuses. Whether this emphasis on the amenities is much more important than the focus on academic instruction and financial aid is the prime concern.Nurturing the industry-academic link has become the crux of how to reform journalism education. Sainath (2001)13 and Sonwalkar (2002)14 felt that the 'corporatization of media industry' in India, on Declining by Degrees: The Effect of Corporatisation on Media Education

14 Sonwalkar, P. (2002). Mudochization of the Indian press: from by-line to bottom-line. Media, Culture and Society, 24, 821-834.

15 Rajagopal, Indhu. 2002. Hidden Academics: Contract Faculty in Canadian Universities. Toronto: University of Toronto Press. 
16 Jones, Glen, Julian Weinrib, Amy Scott Metcalfe, Don Fisher, Kjell Rubenson and Iain Snee. 2012. "Academic Work in Canada: The Perceptions of Early-Career Academics." Higher Education Quarterly 66 (2): $189-206$

par with the 'Murdochization' of media in the West, had an impact on the course curriculum desired in journalism and mass communication education and tilted it in favor of imparting basic skills required for the industry. The shift in goals from the public to the private interest has also altered professional norms of university faculty in ways that undermine faculty academic freedom.

One of the most profound impacts of corporatisation on media education with multifaceted consequences has been the casualization of academic professionals. Many terms have been used to describe this growing segment of academics who work on contracts, including adjuncts, part-timers, sessionals, limited-term employees, lecturers, stipendiaries, etc. Their contracts begin and end with the courses they are appointed to teach. This limited job description means that contract faculty are typically excluded from university governance. Moreover, their salaries are usually in pittance and are paid in terms of lecture taken per week or month. Their benefits are often limited or non-existent, despite the fact that they may have been employed by the same institution for long periods of time.

Contract faculty also differ from one another in many ways, including their life circumstances, level of education, career aspirations, motivations for teaching, and employment status outside the university. Indhu Rajagopal (2002)15 distinguishes between two main groups of contract faculty: "classics" and "contemporaries," each of which has a fundamentally different role within the academy. Classics typically have full-time careers outside of academia, i.e. in industry. For this reason, they may find the conditions of part-time academic work acceptable or even desirable. These hires have been important to universities since their inception, as they provide specialized expertise and connections to new advances in professional fields. Classics, however, are the exception rather than the rule. Most contract academics are not well-paid professionals, but are contemporaries - individuals who usually teach core courses rather than narrow specialties and whose livelihoods are dependent on part-time teaching. Contemporaries comprise a greater proportion of teaching staff in media education and, relative to their numbers, provide a higher proportion of the courses taught. This group also contains a higher proportion of scholars who desire a full-time academic career. Although both groups of contract faculty may value teaching, the practicing professional who teaches courses as part of their personal or professional life is very different than the aspiring academic who teaches multiple courses at substandard wages as a means of earning a living. Overall, then, classics can generally be thought of as "willing" part-timers, while contemporaries are the "real" part-time faculty within the university (Rajagopal 2002: 131, 150).

Contract faculty are generally not required, and usually not encouraged, to participate in university governance. In fact, they are often excluded from even the most basic decision-making bodies, such as departmental committees. In contrast to permanent faculty, who have a substantial degree of input and influence over academic decisions at the department level, contract faculty have little or no input into teaching/curriculum priorities and other aspects of workplace management (Jones et al. 2012).16 The lack of participation of contract staff in academic governance impacts the entire professoriate. It decreases faculty control over the curriculum by allowing administrators more power over its design and priorities. It can also adversely affect the teaching and research commitments of permanent staff because they are assigned all or most of the responsibilities of academic service (e.g., program Declining by Degrees: The Effect of Corporatisation on Media Education reviews, accreditation exercises, student supervision and committee work). In short, most contract faculty have little say in how their departments are run. Even if they do, faculty governance is weakened by constant employee turnover.

Another consequence of this lack of support is that contract faculty are routinely denied access to faculty development programs, including training in pedagogy. Limiting professional enrichment activities to permanent faculty is not only unjust but it threatens the quality of academic programs in which part-timers do most of the teaching. Academic casualization has both direct and indirect impacts on students. The direct impacts stem largely from the fact that substandard pay often forces casual employees to teach multiple courses at a time, sometimes at different institutions. As a result, many are overburdened by heavy teaching loads, and have little time for the writing and research necessary to keep up with their fields. Such a system offers little room for professional growth and development, which means that students of contract instructors are not always exposed to new advances in the field.

Moreover, a study by the Centre for the Future of Higher Education (2012)17 confirms that the "just in time" approach to contract hiring is detrimental for students because it is associated with "insufficient preparation time, insufficient time to incorporate and update meaningful material for students, and insufficient time to explore pedagogical methods and materials" (Street at al. 2012: 7). The study also showed that limited access to pedagogical resources compromised the ability of contract faculty to educate their students. The job insecurity and lack of academic freedom inherent in contract work often translates, indirectly, into impediments to student learning. Contract faculty are evaluated solely in terms of their teaching, which means that student 
evaluations can make the difference between being renewed or being unemployed. In this context, teachers are under pressure to "keep their customers happy" (Puplampu 2004: 177).18

17 August 2012 report of CFHE (Centre for the future of higher education) available at www.futureofhighered.org/research-center/

18 Puplampu, Korbla. 2004. "The Restructuring of Higher Education and Part-Time Instructors: A Theoretical and Political Analysis of Undergraduate Teaching in Canada." Teaching in Higher Education 9 (2): 171-182

\section{LACK OF STANDARDISED MEDIA CURRICULUM}

Media education and the various allied courses offered in our country suffer from lack of standardization. This is also evident from the wide variety of courses and levels of programmes with no accreditation. In the absence of any common framework of journalism and communication education in India, most media universities and private institutions have devised their own modules and course content, which, to some extent, has an unintentional bias towards western models. A large number of text books are of foreign origin with limited relevance to the social, cultural, economic and political realities in India. The profit motive also leads to shortcuts in the educational methods practiced on our children. Like "virtual" instruction.

Most media courses today seem to focus on the medium. The message and the importance of understanding and framing the message according to audience requirements seem to have been lost. The differentiation between varied media courses is as basic as the discussion on what is more important- the message or the medium. Most of the courses are focused on the medium and the dexterity required for using these mediums. Very few courses focus on the message over technology. However, the usage of technology can be made effective only if there is clarity on the message. Thus, it becomes imperative that next-generation media professionals need to be equipped with more than Declining by Degrees: The Effect of Corporatisation on Media Education medium-specific skills. They need to have knowledge to understand the communication processes in the broad socio-political and economic perspective.

\section{CONCLUSION}

The historical, evolving relationship between universities and the business world has been a contentious one for scholars across many generations. Corporatization cannot be viewed as merely the entanglement of universities with business interests because there has never been a period in modern history when universities have been completely free from capital's influence or untouched by corporate practices. In the words of William Carroll (2004: 181)19, today's university campus has been identified as "a site of capital accumulation, a place for creating or enhancing the profit-making capacity of individuals, businesses, or the country itself." As Giroux (2007a: 203) explains, the greatest challenges facing universities today are not technical, instrumental or economic in nature; rather, they centre on the willingness of higher education to confront the "myriad of global problems that produce needless human suffering, obscene forms of inequality, ongoing exploitation of marginalized groups, rapidly expanding masses of disposable human beings, increasing forms of social exclusion, and new forms of authoritarianism."

19 Carroll, William K. (ed). 2004. Critical Strategies for Social Research. Toronto: Canadian Scholars' Press 20 Fredrik DeBoer, PhD in Rhetoric and Composition, Purdue University, May 2015

With ample documentation, media education has become just one more consumer product, with its producers seeking to please the market and minimize dissent or disruption.20 Education, from the earliest years, should be magical and radical. This question regarding privatisation merits serious attention since the purpose of higher education is the creation of knowledge, and the proponents of private education start with the assumption of 'students as the consumers' whose demands of study material and academic grades should be fulfilled since they have paid the requisite fee. Even the assessment of the faculty's performance is done on the basis of students' feedback which may or may not reflect the credentials of a faculty. The corporatization of the media education impacts the research culture and the research process. It changes the priorities and parameters of media research by affecting the selection of topics for investigation, the interpretation of findings and the dissemination of results. Corporatization has, and continues to, directly threaten the education's public service mission, and it is vitally important to subject this process - and its effects - to a critical analysis. Declining by Degrees: The Effect of Corporatisation on Media Education

\section{REFERENCES}

[1]. Aufderheide, Patricia. (2001).Media Literacy: Form a Report of the National Leadership Conference on Media Literacy, in Kubey, R. (Ed.). 2001. Media Literacy in the Information Age: Current Perspectives.

[2]. Buckingham, D. ( 2003a). Media Education and the End of the Critical Consumer. The Harvard Educational Review, 73(3); 309-328.

[3]. COMECE (2001). A Call for Media Education. The Commission of the Bishops' Conferences of the European Community. 30th March 2001 (www.comece.org/upload/pdf/com_media_010330_en.pdf). 
[4]. Das, B. (2005). The Quest for Theory: Mapping Communication Studies in India, in Bel, B. \& al. (Eds.). Media and Mediation. New Delhi: Sage; 35-66.

[5]. Kubey, R. (2001). Media Education: Portraits of an Evolving Field, in Kubey, R. (Ed). Media Literacy in the Information Age: Current Perspectives. Information and Behaviour, 6. New Brunswick, NJ: Transaction Publishers.

[6]. Kumar, K.J. (1995). Media Education, Communication and Public Policy: An Indian Perspective. Bombay: Himalaya Publishing House.

[7]. Livingstone, S. (2001). Children and their Changing Media Environment, in Livingstone, S. \& Bovill, M. (Eds.). Children and Their Changing media Environment: A European Comparative Study. Mahwah, NJ/London: Lawrence Elbaum Associates; 3-21.

[8]. Melkote, S.R. (1991). Communication for Development in the Third World: Theory and Practice. New Delhi: Sage.

[9]. Nandy, A. (1987). Reconstructing Childhood: A critique of the Ideology of Adulthood, in Nandy, A. (Ed.). Essays in the Politics of Awareness. New Delhi: Oxford University Press; 56-76.

[10]. Prinsloo, J. \& Criticos, C. (Eds.). (1991). Media Matters in South Africa. Durban: Media Resource Centre, University of Natal.

[11]. Sanjay, B.P. (2002). Communication Education and Media Needs in India. A Study Conducted by Asian Media Information and Communication Centre of India. Chennai: AMIC-INDIA. 